\title{
Observations of co-seismic broadband electromagnetic waves in the VHF band
}

\author{
K. Shin, M. Nishi, and T. Yoshida \\ Graduate School of Information Sciences, Hiroshima City University, \\ 3-4-1 Ozuka-higashi Asaminami-ku Hiroshima, Hiroshima 731-3194, Japan
}

\begin{abstract}
Many observations have been conducted to clarify the relation between electromagnetic phenomena and seismic activities. We have been observing seismic electromagnetic waves in FM broadcasting frequency band from $76 \mathrm{MHz}$ to $90 \mathrm{MHz}$ using PLL type synthesized digital FM tuners since 1998. We are operating thirteen observatories in Japan. From observations at Ibaraki by the dual frequency method using two different frequencies, nine events of co-seismic electromagnetic waves were observed for seven years from January 1, 2002 to December 31, 2008. Received electromagnetic levels rose up at the same moment of arrival of seismic waves. Further, we examined the relation between the co-seismic broadband electromagnetic waves and the seismic parameters. It was confirmed that the detected peak electromagnetic levels were well correlated with the peak ground accelerations of the earthquakes.
\end{abstract}

Key words: co-seismic broadband electromagnetic wave, VHF band, earthquake, peak ground acceleration.

\section{Introduction}

Many observations have been conducted to clarify the relation between the electromagnetic (hereafter referred to as "EM") phenomena and seismic activities from direct current (DC) to ULF, ELF, VLF, LF and VHF bands with continuous monitoring by various types of observation stations (i.e., Hayakawa et al., 1994; 1999; Nagao, 2001; Rikitake, 2001). Observations of EM phenomena associated with earthquakes are mainly conducted using either (1) direct observational method of seismic EM phenomena (Nagao et al., 2000; Gokhberg et al., 1982; Oike et al., 1994; Fenoglio et al., 1995; Hata et al., 1996; Maeda et al.,1996) or (2) indirect observational method that observe anomalous propagation of artificial radio waves for communications and broadcasting (Hayakawa et al., 1996; Kushida et al., 1998; Sakai et al., 2001). Although many observations have been reported as mentioned above, relations between EM phenomena and seismic activities have been under studying.

We are surrounded with many EM waves such as broadcasting, communication usage and many artificial noises, which may be higher in intensity than that of seismic EM waves. We choose the FM broadcasting frequency band from $76 \mathrm{MHz}$ to $90 \mathrm{MHz}$ in VHF as our observation band. Since this frequency band is assigned for FM broadcasting exclusive use in Japan, it is well administered against other EM interferences. Thus we can set up frequencies for seismic EM wave observations in the FM broadcasting frequency band, which is hardly influenced by artificial and urban EM noises compared with the lower frequency band.

Our observations of seismic EM phenomena using a novel dual frequency method started from 1998. In the past observations, we observed co-seismic EM waves for several earthquakes such as the Tottoriken-seibu earthquake in 2000, the Geiyo earthquake in 2001 and the Mid Niigata prefecture earthquake in 2004 (Yoshida et al., 2001; 2002; 2007). These were observed at the time of arrival of seismic waves and have broadband spectra. It is, however, not confirmed that the relation between the features of the EM waves and the seismic activities.

We are operating thirteen EM observatories in Japan. In the observatories, earthquakes have been most frequently observed at our Ibaraki EM observatory. Thus, we focused on this region for the seismic EM wave observations. As a result of observations, we detected nine broadband EM waves associated 
with earthquakes above level 4 on the Japanese intensity scale for seven years from January 1, 2002 to December 31, 2008. Here, seismic parameters such as the Japanese intensity scale of the earthquake were acquired from the Hitachi K-NET observatory closest to our EM observatory. Further, to clarify the relation between the EM phenomena and earthquakes, we performed analyses of the observed co-seismic broadband EM waves with respect to the seismic parameters.

In this paper, we show the typical example of the co-seismic broadband EM waves observed at the Ibaraki EM observatory. Then, we describe details of the relation between the peak received levels of the EM waves (hereafter referred to as "peak EM level") and the peak ground acceleration levels (hereafter referred to as "peak GA level").

\section{Observation system}

The FM broadcasting frequency band from $76 \mathrm{MHz}$ to $90 \mathrm{MHz}$ is well administered against other EM interferences and hardly influenced by artificial and urban EM noises compared with other lower frequency bands (ITU-R, 1998). We chose this frequency band for the observations of seismic EM waves. In our observations, we have been using the dual frequency method (e.g. Yoshida et al. 2006a). In this method, we set two different frequencies (fn and fr) for the observation channels, which have following characteristics;

fn: This frequency channel is selected from $80.8 \mathrm{MHz}$ to $81.2 \mathrm{MHz}$, not assigned for any FM broadcasting use in Japan,

fr: This frequency channel is selected from $76 \mathrm{MHz}$ to $90 \mathrm{MHz}$ except from $80.8 \mathrm{MHz}$ to $81.2 \mathrm{MHz}$; This frequency channel is used at a remote FM broadcasting station far from the observation site; So the FM broadcasting wave of fr channel is not usually received at the observation site.

If the fluctuation is observed only in fr frequency, the received signal is considered as a FM broadcasting wave reached from a remote station. On the other hand, if the fluctuation is observed in both fn and fr frequencies, the received signal is considered as a broadband EM wave. Using this dual frequency method, we can distinguish broadband EM waves from anomalous propagation of FM broadcasting waves such as duct propagation in the troposphere and reflection from the ionosphere.

Our observation system has been placed in the College of Engineering, Ibaraki University since 2002. We illustrate the configuration of the observation system in Figure 1. As shown in Figure 1, four Yagi-Uda antennas with three elements have been used as a receiving antenna for the EM waves in the VHF band, and have been set on the rooftop of the building of Ibaraki University. Each antenna has been set parallel to the ground and oriented in the directions of north, east, west and south. The observation instruments have been set up inside, and the antennas and eight FM tuners have been connected using

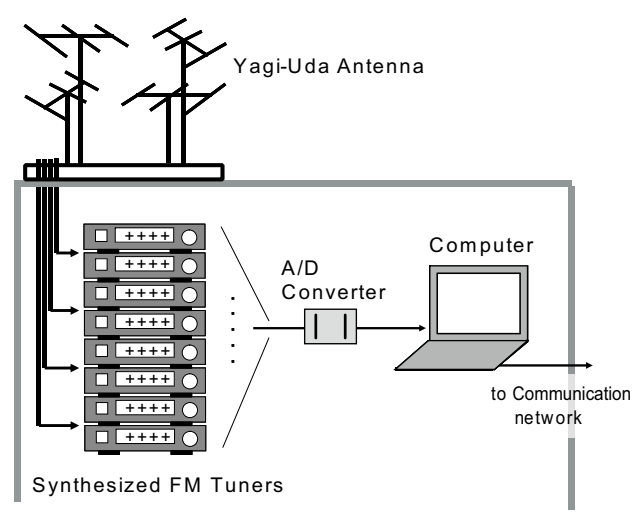

Fig. 1 Observation system at the Ibaraki EM observatory.
Table 1 Specifications of observation system at the Ibaraki EM observatory.

\begin{tabular}{|c|c|}
\hline Receiving antenna & $\begin{array}{l}\text { Yagi-Uda antenna } \\
\text { with three elements }\end{array}$ \\
\hline Receiver & $\begin{array}{l}\text { PLL type synthesized } \\
\text { digital FM tuner }\end{array}$ \\
\hline Receiving bandwidth of $3 \mathrm{~dB}$ & $100 \mathrm{kHz}$ \\
\hline of $30 \mathrm{~dB}$ & $300 \mathrm{kHz}$ \\
\hline of $70 \mathrm{~dB}$ & $400 \mathrm{kHz}$ \\
\hline Limitation of received level & $-120 \mathrm{dBm}(0.001 \mathrm{pw})$ \\
\hline Noise figure & $2 \mathrm{~dB}$ \\
\hline Observation frequency & $76 \mathrm{MHz}-90 \mathrm{MHz}$ \\
\hline Sampling rate & 2 seconds \\
\hline
\end{tabular}


$75 \Omega$ coaxial cables. The received levels have been continuously recorded over a 24 -hours period to a hard disk in a computer via an A/D converter.

We have used PLL type synthesized digital FM tuners (hereafter referred to as "digital FM tuner"). The digital FM tuner has superior receiving characteristics in receiving sensitivity, adjacent channel interference characteristics, and inter-modulation distortion characteristics. We summarize the electrical characteristics of the digital FM tuners of our observation system as follows;

1. Receiving bandwidth of $3 \mathrm{~dB}$ is $100 \mathrm{kHz}$,

2. Noise figure is $2 \mathrm{~dB}$,

3. The received level of the EM wave is related to the received signal strength indicator (RSSI) value of the receivers,

4. The measurement limit of our system is almost equal to $-120 \mathrm{dBm}$ due to the thermal noise of the digital FM tuner.

The specifications of the observation system are summarized in Table 1. In the Ibaraki EM observatory, the data sampling have been performed every two seconds. The state of the observation system and received levels of the EM waves have been monitored in real time by a communication network. The observation time is adjusted based on the GPS clock every hour. The time in the observation results given in this paper is in Japanese Standard Time (JST).

\section{Observation results of Ibaraki-ken-oki earthquake on February 12, 2002}

We have observed the EM waves for seven years from January 1, 2002 to December 31, 2008 at the Ibaraki EM observatory. In this observation period, nine broadband EM waves associated with the earthquakes above level 4 on the Japanese intensity scale have been observed. To clarify the relation between the EM waves and seismic activities, we performed analyses of our observational data.

In this section, we show a typical example of the co-seismic broadband EM wave that has the largest received levels at the Ibaraki EM observatory. The co-seismic broadband EM wave associated with the Ibaraki-ken-oki earthquake of magnitude 5.5 was observed at 22:44:38 JST on February 12, 2002.

Figure 2 shows a map of the epicenter of the Ibaraki-ken-oki earthquake, the Ibaraki EM observatory and the Hitachi K-NET observatory. Both the Ibaraki EM observatory and Hitachi K-NET observatory are almost $39 \mathrm{~km}$ away from the epicenter.

We show the detailed time variations of the co-seismic broadband EM wave and seismic ground accelerations (GA) from 22:43:30 JST to 22:47:30 JST on February 12, 2002 in Figure 3. The first, second and third panels in Figure 3 show time variations of North-South (N-S), East-West (E-W) and

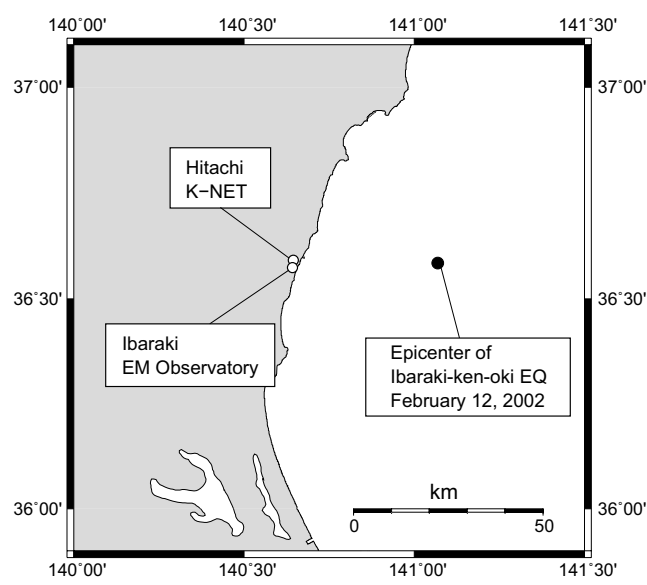

Fig. 2 A map of the Ibaraki EM observatory, the Hitachi K-NET observatory, and the epicenter of the Ibaraki-ken-oki earthquake on February 12, 2002. 


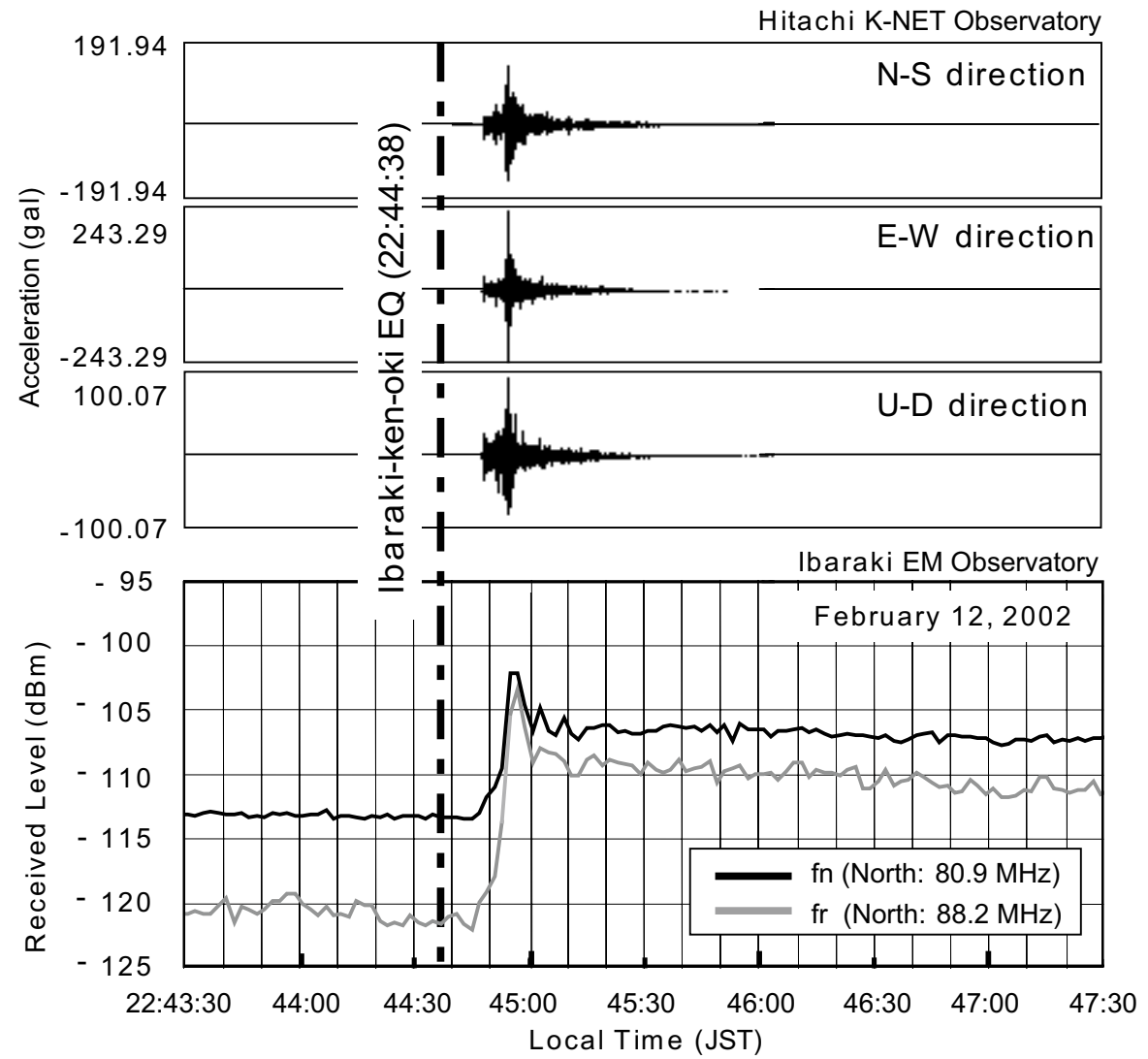

Fig. 3 Time variations of seismic waves (first, second and third panels), and received levels of the EM waves (fourth panel) from 22:43:30 JST to 22:47:30 JST on February 12, 2002.

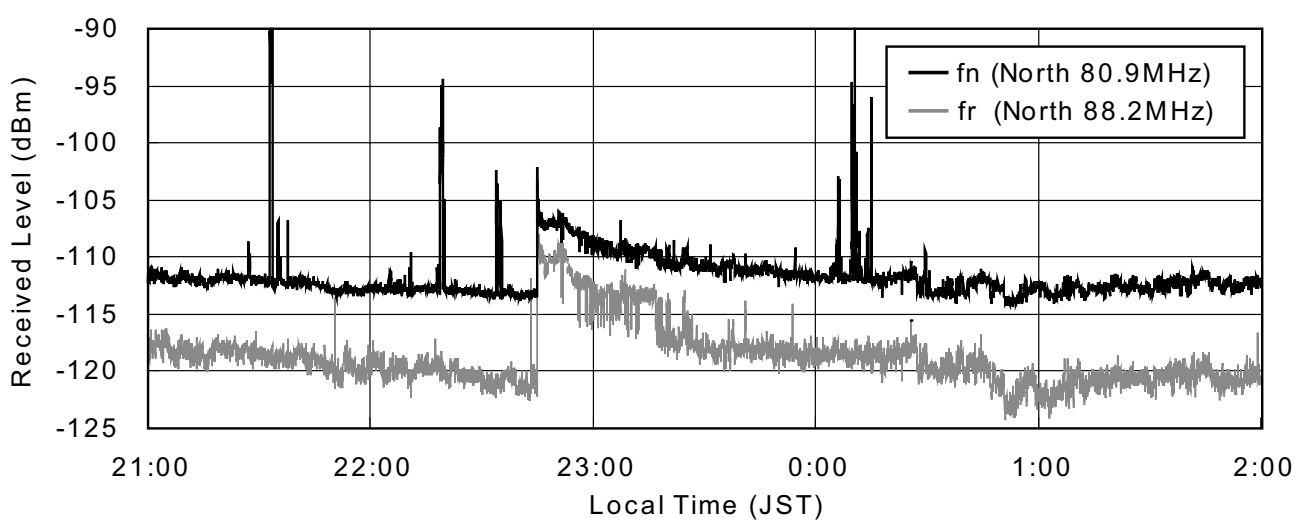

Fig. 4 Time variations of the EM waves from 21:00 JST on February 12 to 2:00 JST on February 13 in 2002. 


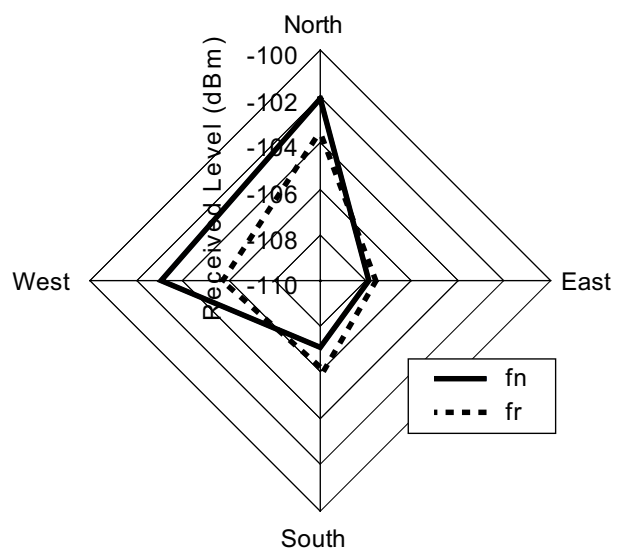

Fig. 5 Peak levels of north, south, east and west directions and the variations in both fr and fn channels of the EM waves observed at 22:44:55 JST on February 12, 2002.

Up-Down (U-D) directions of the seismic waves observed at the Hitachi K-NET observatory. The fourth panel in Figure 3 shows time variations of the EM waves detected toward north direction at the Ibaraki EM observatory. Here, a black solid line and a gray solid line refer to fn $(80.9 \mathrm{MHz})$ and fr $(88.2 \mathrm{MHz})$ channels, respectively.

The Ibaraki-ken-oki earthquake occurred at 22:44:38 JST, as illustrated by the dash-doted line in Figure 3. The peak level of the EM wave was detected at 22:44:55 JST. Since the EM wave was observed in both fr and fn channels as shown in Figure 3, the observed EM wave was thought to be a broadband EM wave. The time of the peak level of the EM wave was corresponding to the arrival time of the seismic wave, not the occurrence time of the earthquake. These results suggest that the detected EM wave rose up to the peak level corresponding to the seismic wave arrival at the Ibaraki EM observatory.

Figure 4 shows the time variations of the EM wave from 21:00 JST on February 12 to 2:00 JST on February 13 in 2002. After received levels of the EM wave rose up at 22:44:55 JST, the received levels of both $\mathrm{fn}$ and fr channels gradually decreased and returned to their normal levels about two hours later.

After carefully checking Figure 4, several spike noises were detected, such as at 21:33 JST, 22:19 JST and 22:33 JST on February 12, 2002. They were only observed in the fn channel. Further, it was confirmed by demodulated sounds of FM tuners that they were caused by amateur radios. These results suggest that they were not broadband noises and not associated with the earthquakes.

Then, the direction of propagation of the EM wave was examined. We show the peak levels of the EM wave, and the variations in both fr and fn channels detected by the north, south, east and west directed antennas in the observation system in Figure 5. Here, a solid line and a dashed line show fn and fr channel outputs, respectively. It was confirmed that the peak level of the EM wave in the Ibaraki-kenoki earthquake was $-102 \mathrm{dBm}$ detected in the north direction, and the EM wave came from northwest. In our other observations, the arrival directions of seismic EM waves were also not toward to the epicenters (Yoshida et al., 2001; 2002). There were the active faults toward their peak EM levels.

\section{Relation between peak EM level and peak GA level}

In the previous section, we have described the co-seismic broadband EM wave which rose up to the peak level corresponding to the motion of earthquake observed at the Ibaraki EM observatory. We describe the relation between the observations of the broadband EM waves and the occurrences of the ground motions in this section. We investigated the earthquakes above level 4 on the Japanese intensity scale. Before 2007, seismic intensities were acquired from the Hitachi-shiyakusho observatory of the Japan Meteorological Agency. In the above criteria, fifteen earthquakes were observed from January 1, 2002 to December 31, 2008. From these earthquakes, we detected nine events of the EM waves 
Table 2 The list of earthquakes above level 4 on the Japanese intensity scale with and without the coseismic broadband EM waves observed at the Ibaraki EM observatory from January 1, 2002 to December $31,2008$.

\begin{tabular}{|c|c|c|c|c|c|c|c|c|c|}
\hline $\begin{array}{l}\text { Origin time of Eq. } \\
(\mathrm{dd} / \mathrm{mm} / \mathrm{yyyy} \text { hh:mm:ss JST) }\end{array}$ & Latitude & Longitude & $\begin{array}{r}\text { Depth } \\
(\mathrm{km})\end{array}$ & $\begin{array}{r}\text { Distance } \\
(\mathrm{km})\end{array}$ & $\mathrm{M}$ & $\begin{array}{r}\text { Peak GA lv. } \\
\text { (gal) }\end{array}$ & $\begin{array}{r}\text { Time of Peak GA } \\
\text { (hh:mm:ss JST) }\end{array}$ & $\begin{array}{r}\text { Peak EM lv. } \\
(\mathrm{dBm})\end{array}$ & $\begin{array}{r}\text { Time of Peak EM } \\
\text { (hh:mm:ss JST) }\end{array}$ \\
\hline $12 / 2 / 200222: 44: 38$ & $36^{\circ} 35.3^{\prime} \mathrm{N}$ & $141^{\circ} 4.9^{\prime} \mathrm{E}$ & 48 & 39 & 5.7 & 263.3 & $22: 44: 55$ & -102.0 & $22: 44: 56$ \\
\hline 21/4/2003 10:18:33 & $36^{\circ} 32.3^{\prime} \mathrm{N}$ & $140^{\circ} 50.9^{\prime} \mathrm{E}$ & 53 & 19 & 4.4 & 135.8 & $10: 18: 48$ & - & - \\
\hline 26/5/2003 18:24:33 & $38^{\circ} 49.2^{\prime} \mathrm{N}$ & $141^{\circ} 39.0^{\prime} \mathrm{E}$ & 72 & 262 & 7.1 & 70.1 & $18: 25: 45$ & - & - \\
\hline 4/8/2003 20:57:14 & $36^{\circ} 26.5^{\prime} \mathrm{N}$ & $140^{\circ} 36.7^{\prime} \mathrm{E}$ & 58 & 17 & 4.9 & 196.7 & $20: 57: 30$ & -106.4 & $20: 57: 37$ \\
\hline 12/11/2003 17:26:42 & $33^{\circ} 9.8^{\prime} \mathrm{N}$ & $137^{\circ} 2.0^{\prime} \mathrm{E}$ & 395 & 501 & 6.5 & 50.0 & $17: 28: 59$ & - & - \\
\hline 23/1/2004 18:01:31 & $37^{\circ} 15.7^{\prime} \mathrm{N}$ & $141^{\circ} 7.6^{\prime} \mathrm{E}$ & 66 & 113 & 5.3 & - & - & -110.0 & $18: 02: 01$ \\
\hline $16 / 8 / 2005$ 11:46:26 & $38^{\circ} 8.9^{\prime} \mathrm{N}$ & $142^{\circ} 16.6^{\prime} \mathrm{E}$ & 42 & 225 & 7.2 & 84.3 & $11: 47: 30$ & -109.3 & $11: 47: 32$ \\
\hline 19/10/2005 20:44:43 & $36^{\circ} 22.9^{\prime} \mathrm{N}$ & $141^{\circ} 2.5^{\prime} \mathrm{E}$ & 48 & 42 & 6.3 & 221.6 & $20: 45: 00$ & -104.9 & $20: 45: 02$ \\
\hline 22/10/2005 22:12:47 & $37^{\circ} 4.7^{\prime} \mathrm{N}$ & $141^{\circ} 7.2^{\prime} \mathrm{E}$ & 52 & 69 & 5.6 & 55.6 & $22: 13: 07$ & -108.0 & $22: 13: 12$ \\
\hline 23/6/2007 23:52:57 & $36^{\circ} 32.9^{\prime} \mathrm{N}$ & $140^{\circ} 48.2^{\prime} \mathrm{E}$ & 53 & 15 & 4.2 & 214.7 & $22: 53: 13$ & -107.0 & $23: 53: 15$ \\
\hline 8/3/2008 1:54:57 & $36^{\circ} 27.1^{\prime} \mathrm{N}$ & $140^{\circ} 36.7^{\prime} \mathrm{E}$ & 57 & 16 & 5.2 & 134.9 & $1: 55: 12$ & -106.2 & $1: 55: 14$ \\
\hline 8/5/2008 1:45:19 & $36^{\circ} 13.6^{\prime} \mathrm{N}$ & $141^{\circ} 36.4^{\prime} \mathrm{E}$ & 51 & 95 & 7.0 & 108.7 & $1: 45: 55$ & -108.1 & $1: 45: 54$ \\
\hline 5/7/2008 16:49:02 & $36^{\circ} 38.5^{\prime} \mathrm{N}$ & $140^{\circ} 57.1^{\prime} \mathrm{E}$ & 50 & 28 & 5.2 & 481.9 & $16: 49: 18$ & - & - \\
\hline 24/7/2008 0:26:20 & $39^{\circ} 43.9^{\prime} \mathrm{N}$ & $141^{\circ} 38.1^{\prime} \mathrm{E}$ & 108 & 359 & 6.8 & 76.0 & $0: 27: 50$ & - & - \\
\hline 22/8/2008 19:59:50 & $36^{\circ} 26.5^{\prime} \mathrm{N}$ & $140^{\circ} 36.9^{\prime} \mathrm{E}$ & 56 & 17 & 5.2 & 149.4 & 20:00:05 & - & - \\
\hline
\end{tabular}

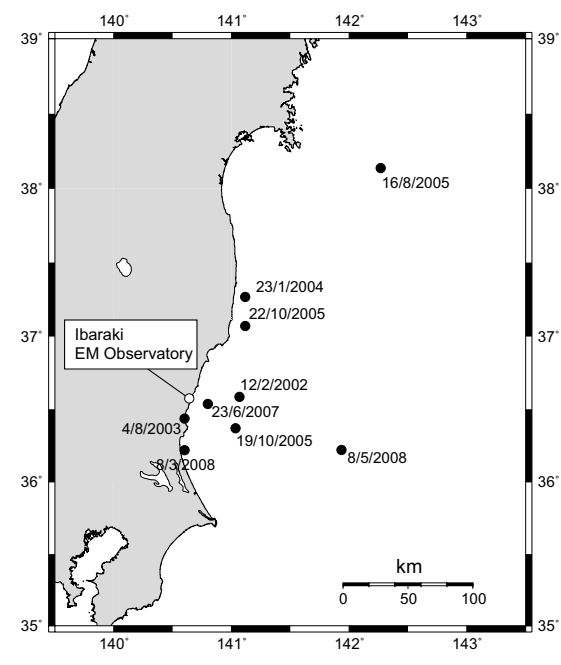

Fig. 6 A map of the Ibaraki EM observatory and the epicenters of the earthquakes relating to the EM waves shown in Table 2.

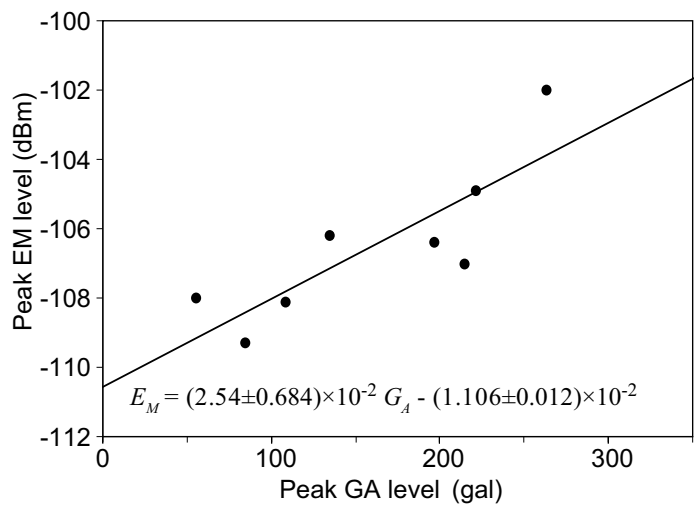

Fig. 7 A relation between the peak EM level and peak GA level.

associated with earthquakes. Table 2 shows the origin time, geographical latitude and longitude, depth, epicentral distance, seismic magnitude, peak GA level and observed time of peak GA of each earthquake. In addition, the peak EM levels and times are listed in Table 2. The Hitachi K-NET observatory did not provide seismic parameters at one EM event observed at January 23, 2004. Figure 6 depicts a map of the Ibaraki EM observatory and the epicenters of the earthquakes relating to the EM waves shown in Table 2. Here, we choose a criterion for EM events as the peak levels of more than $-110 \mathrm{dBm}$ taking into account the measurement limit of our observation system. In six earthquake events shown in Table 2, we could not clearly detect EM waves associated with earthquakes due to artificial noises. Further, we have observed the broadband EM waves without ground motions. In these case, the broadband EM waves were mainly classified as EM waves by the solar flare, galactic noise or lightning (Yoshida et al., 2006a). They can be distinguished from the EM waves associated with the earthquakes.

Next, we show the relation between the peak EM levels and the peak GA levels in Figure 7. The peak EM levels were observed from $-102 \mathrm{dBm}$ to $-110 \mathrm{dBm}$ with respect to the peak GA levels from 55.6 gal to 263.3 gal. There was a correlation that the peak EM level increased corresponding to the 
peak GA level. As observations of co-seismic EM waves at other observatories, we had investigated earthquakes of Tottori-ken-oki earthquake in 2000 and Geiyo earthquake in 2001 (Yoshida et al. 2001; 2002). In observations at our two EM observatories in Hiroshima, there was similar relation that the peak EM level was depending on the peak GA level in above two earthquakes (Yoshida et al. 2006b).

We estimated an equation of the relation between the peak EM level and peak GA level from the observation data by the regression analysis with the standard error. The equation was shown below,

$$
E_{M}=(2.540 \pm 0.684) \times 10^{-2} G_{A}-(1.106 \pm 0.012) \times 10^{-2},
$$

where $E_{M}$ is the peak EM level and $G_{A}$ is the peak GA level. The estimated equation without the standard error is shown as a solid line in Figure 7. As a result of the estimation, a gradient of the relation was $2.54 \times 10^{-2} \mathrm{~dB} / \mathrm{gal}$.

On the other hand, we analysed the relation between the peak EM levels and seismic magnitudes shown in Table 2. There is no correlation between them as contrasted with the relation between the peak EM levels and peak GA levels. For example, the peak EM level was only $-109.3 \mathrm{dBm}$ even though the largest seismic magnitude (M=7.2) was observed on August 16, 2005.

\section{Summary}

We have described the observation results of the co-seismic broadband EM waves observed at our Ibaraki EM observatory. To detect seismic EM waves accurately, we chose the FM broadcasting band from $76 \mathrm{MHz}$ to $90 \mathrm{MHz}$ with PLL synthesized digital FM tuners for the observations. In the observations for seven years from January 1, 2002 to December 31, 2008, we detected nine co-seismic broadband EM wave events. Our observation results are summarized as follows;

1. The observed EM waves had broadband spectra since they were observed in both fr and fn frequencies,

2. The times of the peak levels of the EM waves corresponded to the seismic motion arrival times at the EM observatory, not the occurrence times of the earthquakes,

3. The detected peak EM levels correlated with peak GA levels of the earthquakes.

We are now observing the seismic EM waves at thirteen observatories in Japan. To accumulate observation data, we will continue observations of the EM waves using the dual frequency method.

Acknowledgment. The observed data used in this paper are the result of the observation system set up in Ibaraki University, to which the authors are grateful for its cooperation. Ground strong motion records are provided by Japanese Meteorological Agency and Kyoshin (strong motion) network (K-NET). This work was partly supported by the Grant-in-Aid for Scientific Research No. 20560362.

\section{References}

Fenoglio, M. A., M. J. S. Johnston, and J. D. Byerlee, Magnetic and electric fields associated with changes in high pore pressure in fault zones, Application to the Loma Prieta ULF emissions, J. Geophys. Res., Vol. 100, No. B7, pp. 12951-12958, 1995.

Gokhberg, M. B., V. A. Morgounov, T. Yoshino and I. Tomizawa, Experimental measurement of electromagnetic emissions possibly related to earthquakes in Japan, J. Geophys. Res., Vol. 87, No. B9, pp. 7824-7828, 1982.

Hata, M., X. Tian, I. Takumi, S. Yabashi and A. Imaizumi, ELF horizontal magnetic flux precursor of the moderate M5.8 Yamanashi '96 inland earthquake-A general approach to electromagnetic wave precursor, J. Atmos. Electricity, 16, 199-220, 1996.

Hayakawa, M. and Y. Fujinawa (editors), Electromagnetic Phenomena Related to Earthquake Prediction, Terra Science Publishing Co., Tokyo, 1994.

Hayakawa, M., O. A. Molchanov, T. Ondoh and E. Kawai, Anomalies in the subionospheric VLF signals for the 1995 Hyogo-ken Nanbu earthquake, J. Physics Earth, 44, pp. 413-418, 1996. 
Hayakawa, M. (editor), Atmospheric and Ionospheric Electromagnetic Phenomena Associated with Earthquakes, Terra Science Publishing Co., Tokyo, 1999.

ITU-R, Recommendations Radio wave propagation, P Series-Part 1, p. 372-6, 1998.

Kushida, Y. and R. Kushida, On a possibility of earthquake forecast by radio observation in VHF band, Riken Rev., Vol. 19, pp. 1-13, 1991.

Maeda, K., and N. Tokimasa, Decametric radiation at the time of the Hyogo-ken Nanbu earthquake near Kobe in 1995, Geophys. Res. Lett., Vol. 23, No. 18, pp. 2433-2436, 1996.

Nagao, T., Y. Orihara, T. Yamaguchi, I. Takahashi, K. Hattori, Y. Noda, K. Sayanagi, and S. Uyeda, Coseismic geoelectric potential changes observed in Japan, Geophys. Res. Lett., 27, 10, 1535-1538, 2000.

Nagao, T., New Reviews for Forecast of Earthquakes, Kinmirai Publishing, 2001. (in Japanese)

Oike, K. and T. Yamada, On the relationship between shallow earthquakes and electromagnetic noises in the LF and VLF ranges,Electromagnetic Phenomena Related to Earthquake Prediction, M.Hayakawa and Y.Fujinawa (ed.), Terra Sci. Pub. Co., Tokyo, pp. 115-130, 1994.

Rikitake, T., Forecast of earthquakes, Nihon-senmon-tosho Publishing, 2001. (in Japanese)

Sakai, K., T. Takano and S. Shimakura, Observation system for anomalous propagation of FM radio broadcasting wave related to earthquakes and its preliminary result, J. Atmos. Electricity, Vol. 21, No. 2, pp. 71-78, 2001.

Yoshida, T. and M. Nishi, The observation of broadband co-seismic electromagnetic waves in VHF band, Proc. of IEEE AP-S 2001, pp. 184-187, 2001.

Yoshida, T., K. Yabu and M. Nishi, Observation of co-seismic electromagnetic waves associated with the Geiyo earthquake in 2001, Proc. of IEEE AP-S 2002, pp. 318-321, 2002.

Yoshida, T., M. Nishi and K. Mochizuki, Observations of seismic electromagnetic phenomena in VHF band by dual frequency method, Electr. Eng. Jpn., Vol. 155, No. 4, pp. 36-44, 2006.

Yoshida, T., M. Nishi, S. Takahashi, M. Kobayashi and A. Kaneda, Observation of co-seismic electromagnetic waves in VHF band associated with earthquakes, Proc. of IEEE AP-S 2006, pp. 46714674, 2006.

Yoshida, T., S. Takahashi, and M. Nishi, Propagation characteristics of FM broadcasting waves at the Mid Niigata Prefecture earthquake, Proc. of IEEE ISAP 2007, pp. 446-449, 2007.

(Received April 30, 2011; revised June 2, 2011; accepted June 3, 2011) 